\title{
SoC Estimation and Monitoring of Li-ion Cell using Kalman- Filter Algorithm
}

\author{
M. Premkumar ${ }^{1}$, R. Mohan Kumar ${ }^{2}$, K. Karthick ${ }^{3}$, R. Sowmya ${ }^{4}$ \\ ${ }^{1,3}$ Department of EEE, GMR Institute of Technology, India \\ ${ }^{2}$ Department of EEE, Sri Ramakrishna Engineering College, India \\ ${ }^{4}$ Department of EEE, National Institute of Technology, India
}

\begin{tabular}{l} 
Article Info \\
\hline Article history: \\
Received Jun 22 \\
Revised Sep 6, 2 \\
Accepted Nov 15 \\
\hline Keyword: \\
Electric vehicle \\
KF algorithm \\
Li-ion battery \\
SoC \\
SoH
\end{tabular}

Corresponding Author:

M. Premkumar,

Department of EEE,

GMR Institute of Technology,

Rajam, Andhra Pradesh, India.

Email: premkumar.m@gmrit.org

\begin{abstract}
With the rise in an energy crisis, electric vehicles have become a necessity. An integral part of the electric/hybrid vehicle is batteries. Out of many types, Li-ion batteries are providing features like high power as well as energy density. The features make Li-ion is an excellent choice for multiple applications from electronic appliances to electric vehicles. Li-ion batteries have their limitations while using in electric vehicles, and battery parameter monitoring like temperature, voltage, current, State of Charge (SoC), etc. is very much essential. The monitoring is dependent on actual physical measurements, which are subject to error contributing factors such as measurement noise, errors etc. With the estimation of SOC and State of Health $(\mathrm{SoH})$ of the battery model, the lifetime of the battery will be calculated out, and along these lines sparing significant cost. In this paper, a study on SoH estimation and Li-ion battery SoC is estimated using a Kalman Filter (KF) algorithm estimation and results are presented to validate the Liion operating performance.
\end{abstract}

Copyright $\odot 2018$ Institute of Advanced Engineering and Science. All rights reserved.

\section{INTRODUCTION}

Nowadays, Li-ion batteries are widely used in various types of applications which have a comparatively small size range of device use into large size type application. This type of batteries has attracted the interest of several industries because of its advantages compared to other rechargeable batteries [1]. The energy density of Li-ion batteries is high, and it requires less maintenance. It also has a high nominal voltage, with the slow self-discharging also no exhibits effected on the memory. This merit makes in Li-ion batteries are mostly used technologies for energy problems and automobile applications. The performance of Li-ion batteries degrades over a period because they are highly sensitive to temperature and sometimes they are also unsafe when they are overcharged. With the help of a battery management system (BMS), the drawbacks are avoided. This type of system controls both charging as well as discharging of batteries and provided the reliable, safety operation as well as ensuring the longevity of the batteries. It is also capable of handling additional tasks and controls the temperature of the battery. Such tasks need to consider two main parameters: i) $\mathrm{SoC}$ and ii) $\mathrm{SoH}$ of the battery. State of charge is defined as saved energy to maximum energy saved in that battery [2]. There are different types of methods are used for the state of charge calculation and estimation such as open circuit voltage method, Kalman filter estimation, state method, Coulomb counting method, AH integral method etc. In Electric Vehicles, when calculating of state of charge by using Coulomb 
counting method, there is a problem in setting initial condition, which is not always necessarily known and another issue is being the error will take much more time to sense the signal from sensor [3]-[6].

In Li-ion batteries, consider any cell that depended upon the requirement of electronic consumer, temperature, significant current flow through the battery. The different type of Li-ion battery cells is graphite, Carbon, Carbon and LFP [7], [8]. SoC estimation and monitoring are done with the help of different model like resistance-capacitance based model, Thevenin's type model, Ohmic base model and open circuit voltage adding the type of model etc. [9]-[11]. The controlling is achieved with the help of KF, and it has been applied for state observe as well as predicted problems [12]. The primary battery model is converted into the state space variable model as discussed in [13]. In this article, the battery model is converted into the state space model representation using KF estimation. For maintaining proper battery performance, the methods such as the diagnostic method and prognostic method are used. In Li-ion battery, overcharging and over depletion is taking place, and it damages the battery. The vital point to be considered for battery iagnostics is state of health $(\mathrm{SoH})$, which measures the battery capacity of energy storage as well as delivered power [14], [15].

\section{MODELLING OF LI-ION CELL}

In this article, basic modelling of the cell is the same as the Li-ion battery modelling. The Li-ion cell modelled with the help of RC model. Two RC (resistance-capacitance) type of model selected for analysis and each dynamics battery model have adopted the state variable equations [10]. The equivalent circuit of the cell is shown in Figure 1.

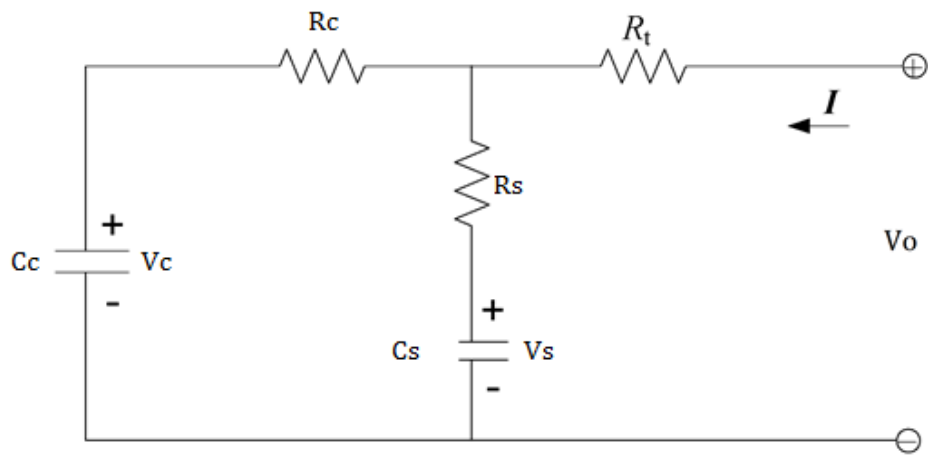

Figure 1. 2RC model of the battery

In Figure 1, the two single RC model are connected in the parallel. One RC model represents charging that is R_c (charging resistances) and C_c (charging capacitance) and the second RC model represents discharging that is $\mathrm{R}_{-}(\mathrm{s})$ (surface resistance) and $\mathrm{C}_{-} \mathrm{s}$ (surface capacitance), and Ohmic resistance is represented byR_t. The voltage across respective RC model is V_c and V_s. The various elements in modelling is used to study the dynamic behavior of the battery under different operating situations.

\subsection{The mathematical derivation of the model}

The modelling is done for converting the basic model to state variable form. When converting into the state variable form, it necessary to find out the state variable. Consider three state variable that is V_c, V_s and V_o for modelling. Here, V_o is the output voltage of the cell. KVL is applied on figure 1 to derive the output voltage and it is represented in (1) and (2).

$$
\mathrm{V}_{\mathrm{o}}=\mathrm{IR}_{\mathrm{t}}+\mathrm{I}_{\mathrm{c}} \mathrm{R}_{\mathrm{c}}+\mathrm{V}_{\mathrm{c}}
$$

Similarly,

$$
V_{\mathrm{o}}=\mathrm{IR}_{\mathrm{t}}+\mathrm{I}_{\mathrm{s}} \mathrm{R}_{\mathrm{s}}+\mathrm{V}_{\mathrm{s}}
$$

Subtract the Eq. 1 and Eq. 2, and we get the equation as follows in (3).

$$
I_{S} R_{s}=I_{c} R_{c}+V_{c}-V_{s}
$$


By applying Kirchhoff's law, the load current through the cell is derived, and it is represented in (4).

$$
\mathrm{I}=\mathrm{I}_{\mathrm{c}}+\mathrm{I}_{\mathrm{s}}, \mathrm{I}_{\mathrm{s}}=\mathrm{I}-\mathrm{I}_{\mathrm{c}}
$$

By substituting (4) in (3) and (5) is derived for further analysis.

$$
\mathrm{I}_{\mathrm{s}}\left(\mathrm{R}_{\mathrm{c}}+\mathrm{R}_{\mathrm{s}}\right)=\mathrm{IR}_{\mathrm{s}}+\mathrm{V}_{\mathrm{s}}-\mathrm{V}_{\mathrm{c}}
$$

The current through the charging capacitor is represented in (6).

$$
\mathrm{I}_{\mathrm{c}}=\mathrm{C}_{\mathrm{c}} \frac{\partial \mathrm{V}_{\mathrm{c}}}{\partial \mathrm{t}}
$$

The charging capacitor voltage is derived by substituting (6) in (5).

$$
\dot{\mathrm{V}}_{\mathrm{c}}=\frac{\mathrm{IR}_{\mathrm{S}}}{\mathrm{C}_{\mathrm{c}}\left(\mathrm{R}_{\mathrm{c}}+\mathrm{R}_{\mathrm{s}}\right)}+\frac{\mathrm{V}_{\mathrm{s}}}{\mathrm{C}_{\mathrm{c}}\left(\mathrm{R}_{\mathrm{c}}+\mathrm{R}_{\mathrm{s}}\right)}-\frac{\mathrm{V}_{\mathrm{c}}}{\mathrm{C}_{\mathrm{c}}\left(\mathrm{R}_{\mathrm{c}}+\mathrm{R}_{\mathrm{s}}\right)}
$$

Similarly, the discharging capacitor voltage is derived, and it is represented in (8).

$$
\dot{V}_{s}=\frac{I_{c}}{C_{s}\left(R_{c}+R_{s}\right)}+\frac{V_{c}}{C_{s}\left(R_{s}+R_{c}\right)}-\frac{V_{s}}{C_{s}\left(R_{s}+R_{c}\right)}
$$

Let consider the following constants for analysis, $a_{1}=1 / C_{c}\left(R_{c}+R_{s}\right), b_{1}=1 / C_{s}\left(R_{c}+R_{s}\right)$ and substitute in (7) and (8).

$$
\begin{aligned}
& \dot{\mathrm{V}}_{\mathrm{c}}=\mathrm{a}_{1} I_{\mathrm{s}}+\mathrm{a}_{1} \mathrm{~V}_{\mathrm{s}}-\mathrm{a}_{1} \mathrm{~V}_{\mathrm{c}} \\
& \dot{\mathrm{V}}_{\mathrm{s}}=\mathrm{b}_{1} I \mathrm{R}_{\mathrm{c}}+\mathrm{b}_{1} \mathrm{~V}_{\mathrm{c}}-\mathrm{b}_{1} \mathrm{~V}_{\mathrm{s}}
\end{aligned}
$$

By adding (1) and (2), (11) is derived.

$$
2 V_{\mathrm{o}}=2 \mathrm{IR}_{\mathrm{t}}+\mathrm{I}_{\mathrm{c}} \mathrm{R}_{\mathrm{c}}+\mathrm{I}_{\mathrm{s}} \mathrm{R}_{\mathrm{s}}+\mathrm{V}_{\mathrm{c}}+\mathrm{V}_{\mathrm{s}}
$$

By applying current division rule, and the above (11) is replaced by (12).

$$
\mathrm{V}_{\mathrm{o}}=\frac{\left(\mathrm{V}_{\mathrm{c}}+\mathrm{V}_{\mathrm{s}}\right)}{2}+\left(\mathrm{R}_{\mathrm{t}}+\mathrm{D}\right) * \mathrm{I}
$$

Where $D=\frac{R_{c} * R_{s}}{\left(R_{c}+R_{S}\right)}$. Let consider the rate of change of current is nearly equal to zero. The (12) is simplified in (13).

$$
\dot{\mathrm{V}}_{\mathrm{o}}=\frac{\left(\dot{\mathrm{V}}_{\mathrm{c}}+\dot{\mathrm{V}}_{\mathrm{s}}\right)}{2}
$$

Substitute (9) and (10) in (13), the output voltage is derived as (14).

$$
2 \dot{\mathrm{V}}_{\mathrm{o}}=\left(\mathrm{b}_{1}-\mathrm{a}_{1}\right) \mathrm{V}_{\mathrm{c}}+\left(\mathrm{a}_{1}-\mathrm{b}_{1}\right) \mathrm{V}_{\mathrm{s}}+\left(\mathrm{a}_{1} \mathrm{R}_{\mathrm{s}}+\mathrm{b}_{1} \mathrm{R}_{\mathrm{c}}\right) \mathrm{I}
$$

From (12), $\mathrm{V}_{\mathrm{c}}$ is obtained and substitute in (14) and the output voltage is further simplified as (15).

$$
\dot{\mathrm{V}}_{\mathrm{o}}=\left(\mathrm{b}_{1}-\mathrm{a}_{1}\right) \mathrm{V}_{\mathrm{c}}+\left(\mathrm{a}_{1}-\mathrm{b}_{1}\right) \mathrm{V}_{\mathrm{o}}+\left(\left[\mathrm{a}_{1}\left(0.5 \mathrm{R}_{\mathrm{s}}+\mathrm{R}_{\mathrm{t}}+\mathrm{D}\right)+\mathrm{b}_{1}\left(0.5 \mathrm{R}_{\mathrm{c}}-\mathrm{R}_{\mathrm{t}}-\mathrm{D}\right)\right] \mathrm{I}\right.
$$

From (9), (10) and (15), the state variable matrix is represented as (16).

$$
\left[\begin{array}{c}
\dot{V}_{\mathrm{c}} \\
\dot{\mathrm{V}_{\mathrm{s}}} \\
\mathrm{V}_{\mathrm{o}}
\end{array}\right]=\left[\begin{array}{ccc}
-\mathrm{a}_{1} & \mathrm{a}_{1} & 0 \\
\mathrm{~b}_{1} & -\mathrm{b}_{1} & 0 \\
\left(\mathrm{~b}_{1}-\mathrm{a}_{1}\right) & 0 & \left(\mathrm{a}_{1}-\mathrm{b}_{1}\right)
\end{array}\right] *\left[\begin{array}{c}
\mathrm{V}_{\mathrm{c}} \\
\mathrm{V}_{\mathrm{s}} \\
\mathrm{V}_{\mathrm{o}}
\end{array}\right]+\left[\begin{array}{c}
\mathrm{a}_{1} \mathrm{R}_{\mathrm{s}} \\
\mathrm{b}_{1} \mathrm{R}_{\mathrm{c}} \\
\mathrm{a}_{1}\left(0.5 \mathrm{R}_{\mathrm{s}}+\mathrm{R}_{\mathrm{t}}+\mathrm{D}\right)+\mathrm{b}_{1}\left(0.5 \mathrm{R}_{\mathrm{c}}-\mathrm{R}_{\mathrm{t}}-\mathrm{D}\right)
\end{array}\right] * \mathrm{I}
$$


According to operating condition and SoC of the battery, the values of $\mathrm{R}_{s}, \mathrm{R}_{\mathrm{c}}, \mathrm{C}_{\mathrm{s}}, \mathrm{C}_{\mathrm{c}}$ will be different. Thus different values will result in different state space model. (16) is used for SoC estimation and Kalman Filter algorithm. Detailed Kalman Algorithm was applied on this model in Matlab/Simulink programming environment to simulate theoretical results. The values are listed in Table 1.

Table 1. Parameter for different SoC

\begin{tabular}{ccc}
\hline SoC & $50 \%$ & $60 \%$ \\
\hline $\operatorname{Rs}(\Omega)$ & 0.00651 & 0.00651 \\
$\operatorname{Rc}(\Omega)$ & 0.01776 & 0.01776 \\
$\operatorname{Cs}(\mathrm{F})$ & 24.73 & 27.6 \\
$\operatorname{Cc}(\mathrm{F})$ & 58103 & 70266 \\
$\operatorname{Rt}(\Omega)$ & 0.01954 & 0.01954 \\
\hline
\end{tabular}

For different SoC values, resistance and capacitance are varied due to the different charge stored in the battery. A MATLAB model obtains these values of $\mathrm{R}$ and $\mathrm{C}$ with different SoCs. This gives a common idea of how the battery performs for different SoCs. For the state space model, check the controllability and observability by using Kalman method.

\section{MONITORING OF LITHIUM-ION BATTERY}

Depend upon the requirements and the current rating, consider any type of lithium-ion battery and also consider extended life capacity. In this article, Li-ion ( $\mathrm{LiCoO} 2)$ cell type battery [8] is taken for analysis. The battery parameters such as SoC, current, voltage and temperature is monitored. The parameter monitoring is done with the help of Matlab/Simulink. The Matlab/Simulink model is shown in Figure 2 and Figure 3.

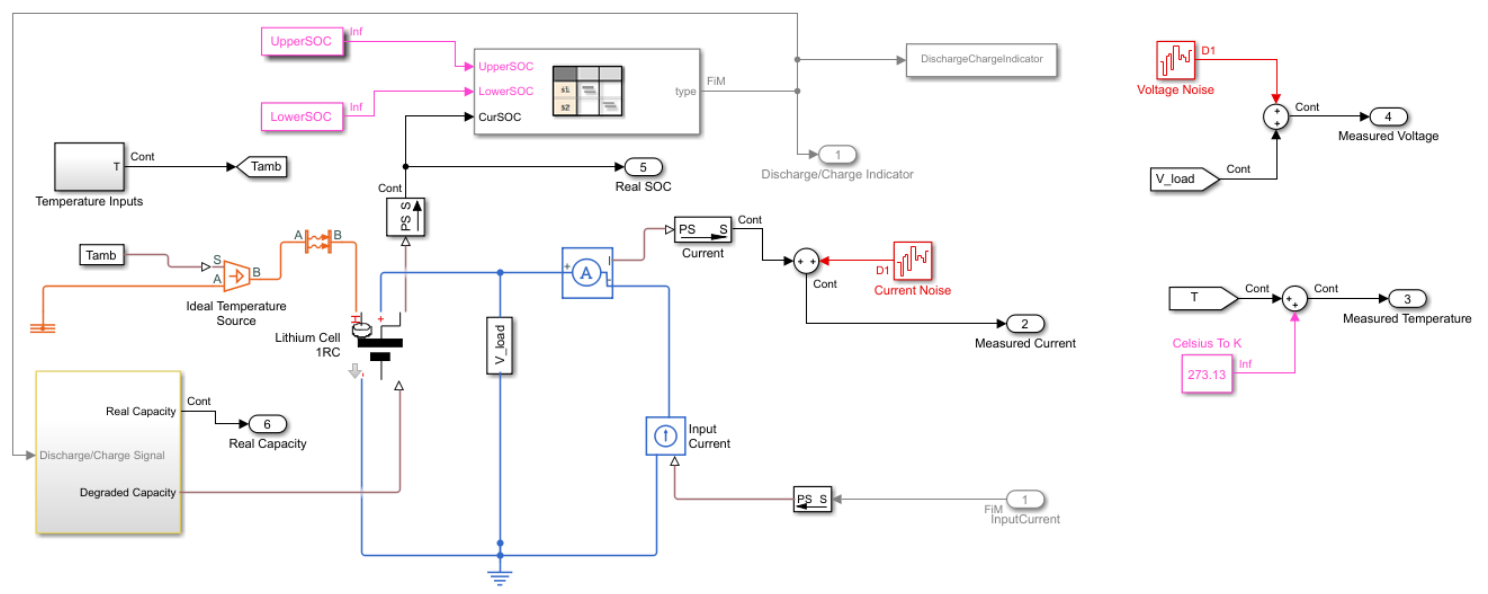

Figure 2. Block diagram for parameter monitoring in MATLAB

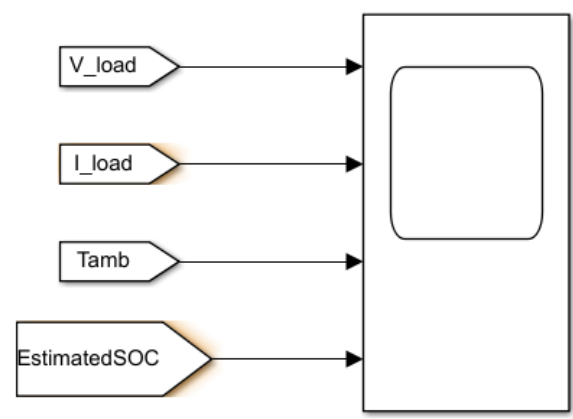

Figure 3. Parameters scope in MATLAB 
PS Simulink converter that converts the physical signal into the Simulink output signal in scope. The model uses two types of input signals, i.e. input current and ambient temperature taken at $20^{\circ} \mathrm{C}$ constant. The energy transfer between two points is done with the help of convection fluid motion. Energy transfer process is done with the cooling law of Newton. This law states that the convection heat transfer directly proportional to the convection heat transfer coefficient, temperature difference and surface area. Consider two points A1 and B1 connected for convective heat transfer. Between these, energy transfer from A1 to B1, i.e. Positive heat flow and vice versa. Take natural convection heat transfer coefficient $5-25 \mathrm{~W} / \mathrm{m}^{2} / \mathrm{K}$.

The thermal energy of the ideal source, i.e. efficiently sustainable in maintaining the specific temperature and in this system output is split into the consumed of heat. Block connected between A2 and B2 correspond to the temperature source of input and output side port respectively. Temperature difference that is the temperature at points (A2-B2) across the source is directly proportional to the control signal.

Thermal reference is equivalent to electrical ground or reference used in the circuit. It gives constant value as a reference, be it 0 or any other ref value. This is a point with which all other temperatures are measured in the system. Each physical network is connected to one solver block. Without that block, the output cannot be obtained as this block helps to solve operation. All blocks are coded internally.

\subsection{State of Charge (SoC)}

State of charge is defined as saved energy to maximum energy that can be saved in that battery. SoC is calculated in percentage. Where $100 \%$ indicates wholly charged, and $0 \%$ indicates wholly discharged. This is for one cell; however, if the battery is considered as a whole, it has multiple cells. A battery pack which has few individual cells in parallel could be taken as one cell with higher voltage, and current limits and SoC will be determined. However, it is always better to calculate SoC without assuming battery pack as a single cell. It is better for performance evaluation and consistency. If limit and SoC of all comprising cells in the battery pack are known, then, the event that there are exceptional productivity and non-loss adjusting gadget, then the State of Charge of the given battery system is represented in (17).

$$
\text { SoC }=\frac{\sum \operatorname{SOC}_{\mathrm{i}} * \mathrm{C}_{\mathrm{i}}}{\sum \mathrm{C}_{\mathrm{i}}}
$$

With SoC estimation, considerable time is saved, required in battery testing. During actual testing of battery, with fully charged and then discharging, SoC estimation saves time by predicting battery performance with modelling. Also, it has its issues with actual testing of battery, viz. long duration, the requirement of current pulses etc. Kalman Filter algorithm is the process used for estimating the State of Charge of the battery. With a forecast of state of charge of the battery, its lifetime will be calculated, and this is economic, as it saves the time required for actual testing. In this article, SoC estimation with the help of Kaman filter [10] is discussed.

For SoC estimation using Kalman Filter, state space model discussed in the mathematical section was used. For SoC using a Kalman filter process, to simulate, the random noise is added with the input, to check whether the performance of Kalman Filter is sufficiently satisfying for Li-ion Battery SoC estimation. Kalman filter primarily works on prediction and updating sequence based on data. Prediction involves prediction of state estimate and prediction of estimated covariance. Updating involves innovation on estimated covariance, calculation of residues from known data and finally, calculation of Kalman gain, which is again used for updating purpose. Again estimate of states and covariance is updated based on prior knowledge, posterior knowledge and obtained Kalman gain. This process is followed for the Kalman filter as estimation. Necessary inputs for this state representation given in (16), initial guesses for covariance, all of which are done in MATLAB programming.

Kalman filtering is an algorithm which uses state measurements over time and having noise and various other inaccuracies and uncertainties and gives an estimate of unknown state values from available data. These values of estimated states are more accurate than based on other measurements. Kalman filtering uses Bayesian estimation process, and joint probability distribution for each sampling instance. Kalman filter algorithm consists of two steps. During the prediction stage, the algorithm estimates the current value of states. Once the next sample of data arrives, which also has noise and uncertainties of process and measurement noise, that estimate is updated according to new measurements. This process is recursive, i.e. it repeats for each sampling instant, and it requires only previous time instant and current measurement to estimate the current state. Kalman filter includes estimation of noise covariance matrices that are used for the process. The Kalman filter is the linear filter when it follows three conditions such as the model perfectly matches actual process under consideration, the noise in the system is white noise, and finally, the covariances of the noise are precisely known. There are different types and versions of the Kalman Filter. For the non-linear system, Kalman filter is not applied directly, so that introduces Extended Kalman Filter (EKF) or Unscented Kalman Filter (UKF). This work focusses on a linear system with direct Kalman filter. 


\subsection{SoH Estimation}

The battery's storage capacity and supply electrical energy are known as the battery state of health $(\mathrm{SoH})$. SoH provides information about the battery energy or its power. New SoH estimation methods are discussed taking into account the battery energy. The method discussed in this paper is a non-linear model method. The logistic growth curve is used to model the Ah, and the voltage function is represented in (18).

$$
\mathrm{F}(\mathrm{x})=\mathrm{P}+\frac{\mathrm{C}}{\left\{1+\operatorname{Sexp}\left[-\beta\left(\mathrm{x}-\mathrm{x}_{0}\right)\right]\right\}^{\frac{1}{s}}}
$$

where $\mathrm{P}=$ Lower Limit Value, $\mathrm{c}=$ Upper Limit Value, $\mathrm{S}=$ Symmetrical point, $\beta=$ Growth Rate, $\mathrm{X}_{\mathrm{o}}=$ Inflection Point. The estimated battery SoH is evaluated using Eq.18 and given in (19).

$$
\mathrm{SOH}_{\mathrm{est}}=\left(\frac{(\text { Cest })_{\mathrm{x}}}{(\text { (est) }}\right) * 100
$$

where the subscripts $\mathrm{y}$ and $\mathrm{x}$ shows the number of tests iteration. The battery SoH for every data set is evaluated and then compared with the $\mathrm{SoH}$ which is estimated. However, in this paper, the estimation of the SoC has been presented.

\section{SIMULATION RESULTS}

The Li-ion cell is mathematically modeled as per the (1)-(16) using Matlab/Simulink simulation software. The cell is simulated and the SoC is measured and estimated using two methods such as isothermal pulse discharge experiment [16] and KF algorithm. The comparison results for the both cases are presented for the better understanding of effective parameter estimation method.

\subsection{Case 1: Isothermal Pulse Discharge Experiment}

The Figure 4-6 shows the different simulation waveforms of the Li-ion cell for the SoC with the initial assumption of $50 \%$ SoC. Figure 4 presents the input taken by the cell during charging and discharging period of the cell.

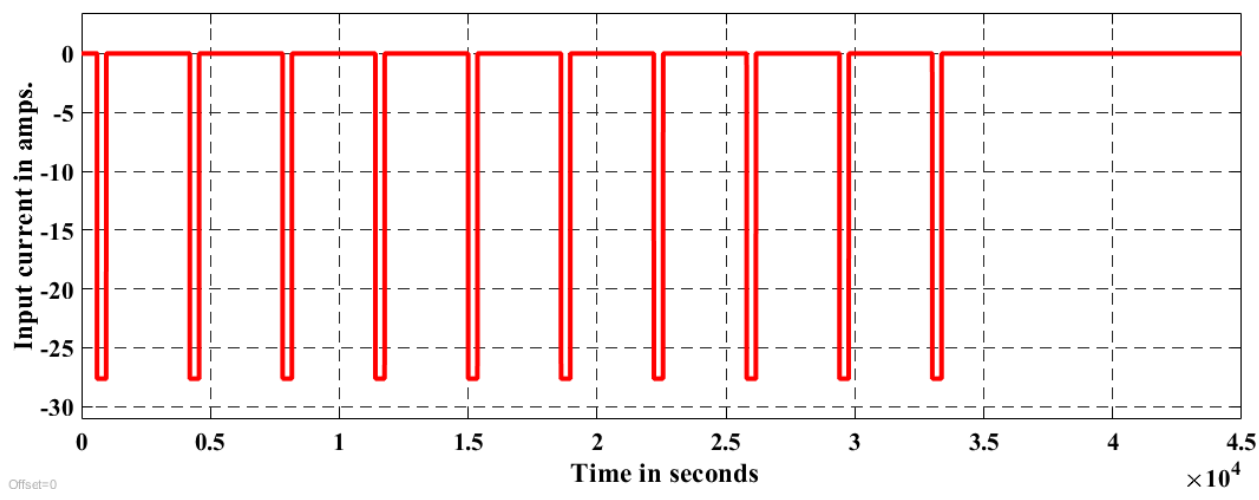

Figure 4. Input current during charging and discharging

Figure 5 shows the input voltage and output voltage for the cell during both the charging and discharging condition. Figure 6 presents the SoC estimation over the period of 12.5 hours of charging and discharging condition. From the figure, it is observed that over the period of 9.44 hours, the SoC reaches 0 . However, the estimated SoC is not up to the expected result.

So, the cell's SoC is estimated using the convention KF algorithm to overcome the drawbacks by the isothermal pulse discharge method. Finally, it is observed that the estimated parameter shows the more error covariance by the conventional isothermal pulse discharge experiment method. 


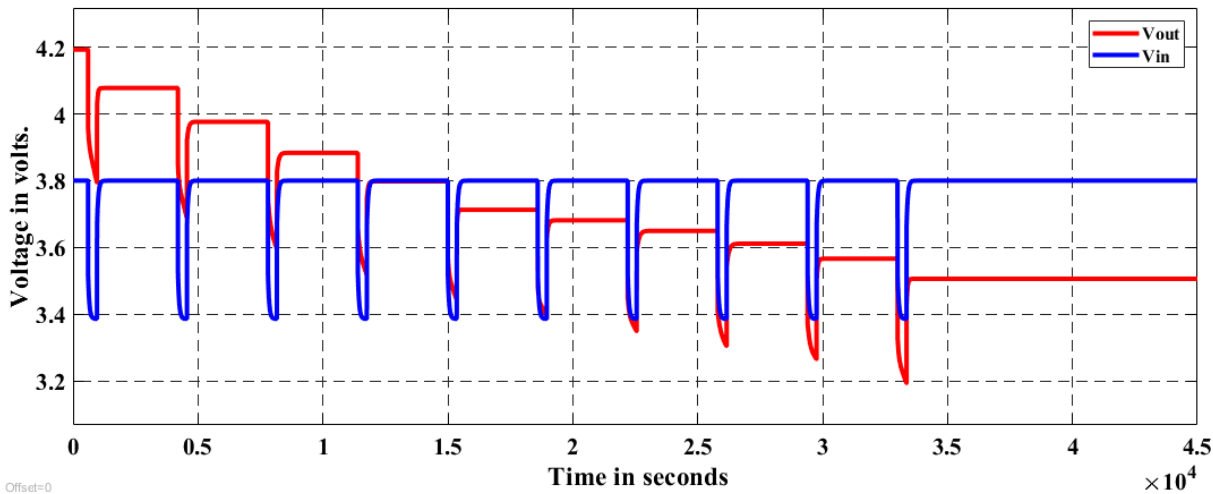

Figure 5. Cell terminal voltage and input voltage over the period

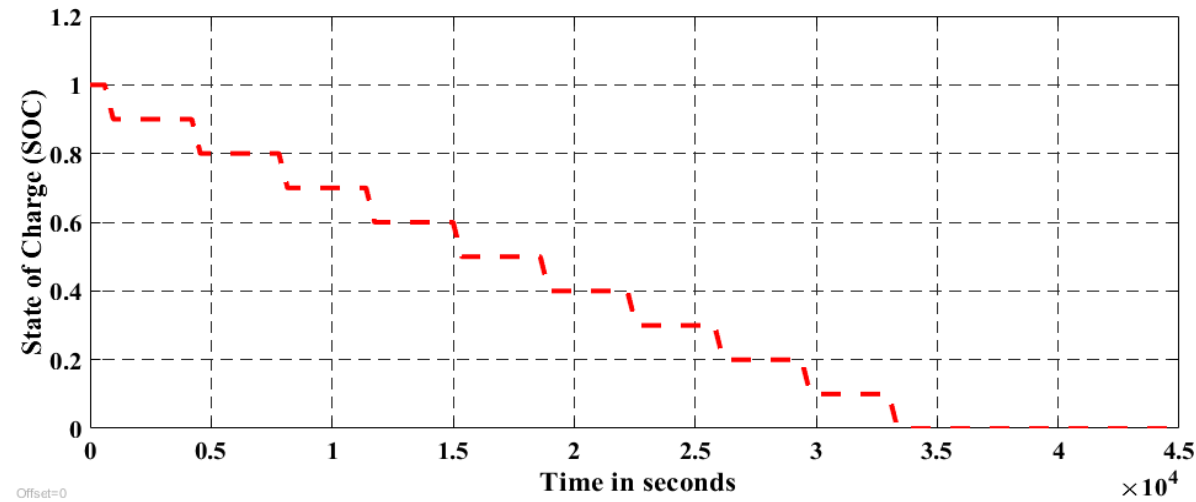

Figure 6. SoC estimation using isothermal pulse discharge method over the period

\subsection{Case 2: Estimation using KF algorithm}

The drawbacks of the method proposed in [16] are overcome by the conventional KF algorithm. The $\mathrm{KF}$ algorithm is modeled in Matlab/Simulink and the thermal effect on the Li-ion cell also considered during simulation to effectively validate the experimental results. Figure 7 shows the temperature variation in Kelvin over the period of charging and discharging.

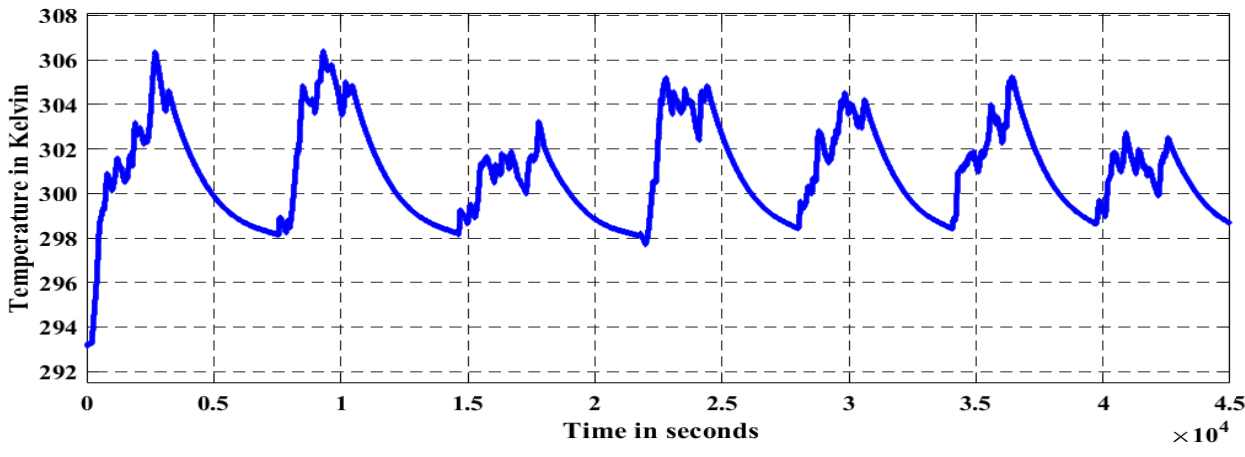

Figure 7. Temperature variation in Kelvin over the finite time

Figure 8 shows the comparison between the estimated SoC, and measured SoC. Both measured and estimated $\mathrm{SoC}$ is matching, and it displays a small error covariance i.e. approximately $1.5 \%$. However, this error is in the accepted level. The battery capacity is estimated using KF algorithm, and it is compared with the measured capacity. There is a small mismatch due to the battery thermal effects. The estimated battery capacity and the random current signal is shown in Figure 9. 
Figure 10 shows the charging and discharging indication of the cell, and it is used to estimate the input current taken by the cell during charge/discharge. Figure 11 shows the comparison of the SoC estimation using both the isothermal pulse discharge experiment method, and the conventional KF algorithm. From the Figure 11, it is observed that the KF algorithm estimates the SoC effectively and accurately, and the estimated SoC is matching with the actual value of SoC.
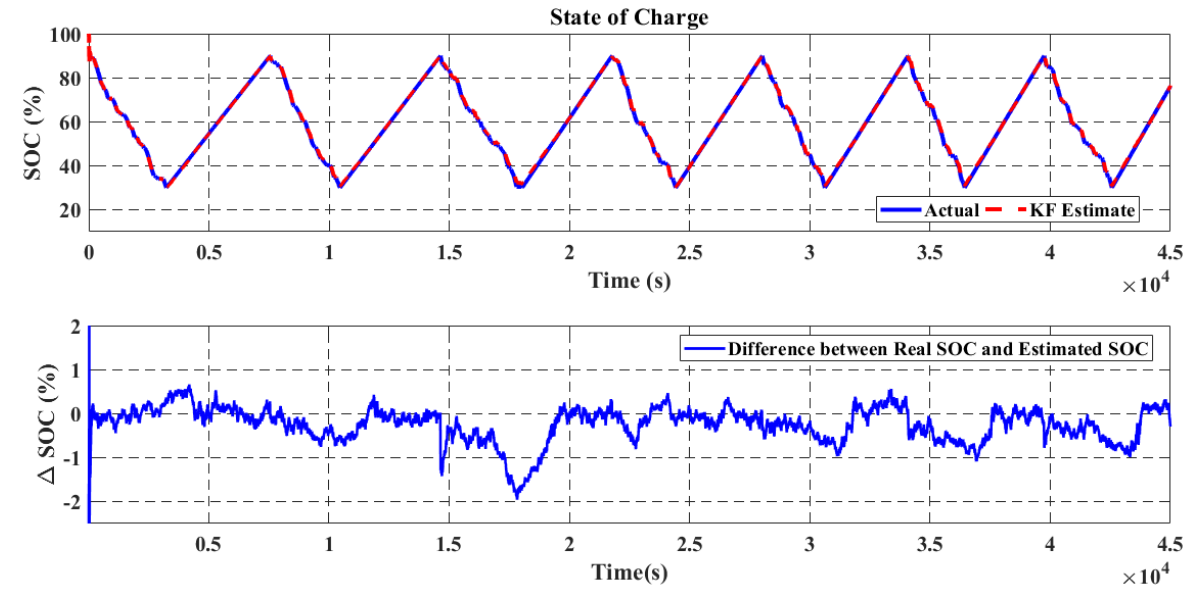

Figure 8. Output response of the cell and error covariance over the period of charge/discharge
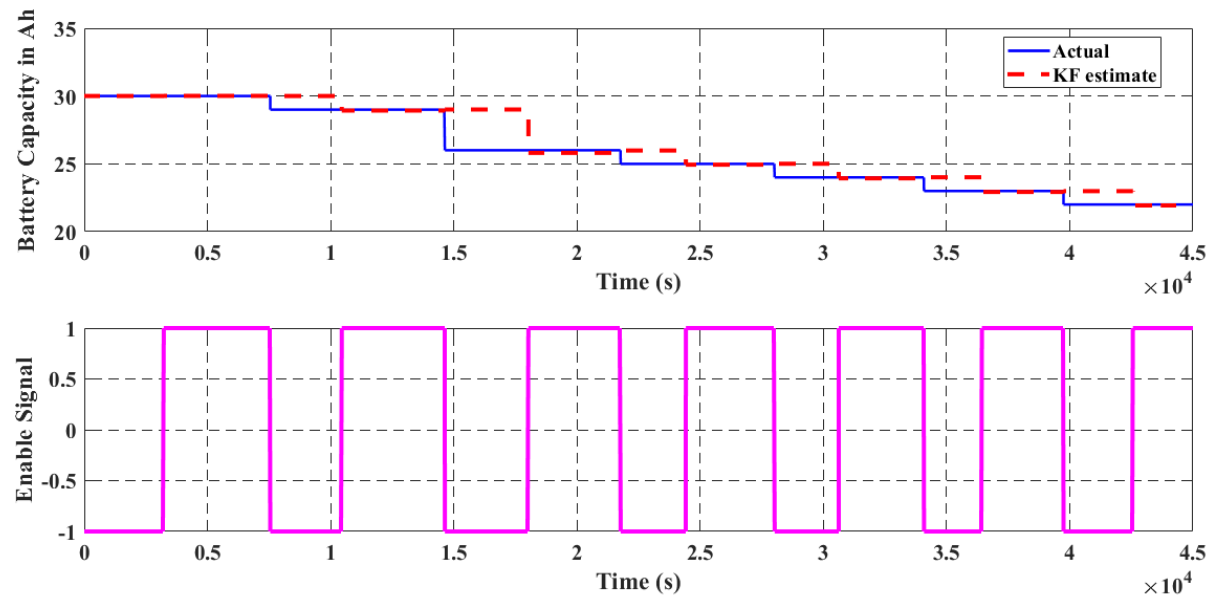

Figure 9. Estimated battery capacity using KF algorithm and random current signal

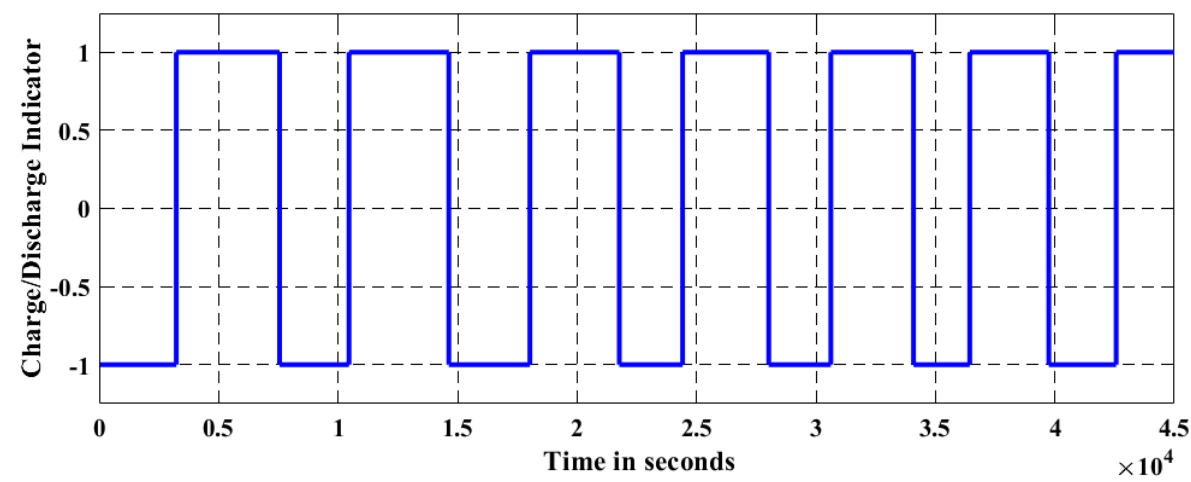

Figure 10. Charging and discharging indication 
Maintaining the mean value of the cell voltage $3.267 \mathrm{~V}$ which is near to the actual value of the cell terminal voltage. The error recorded over the period is shown in Figure 12, and error is maintained within the acceptance band.

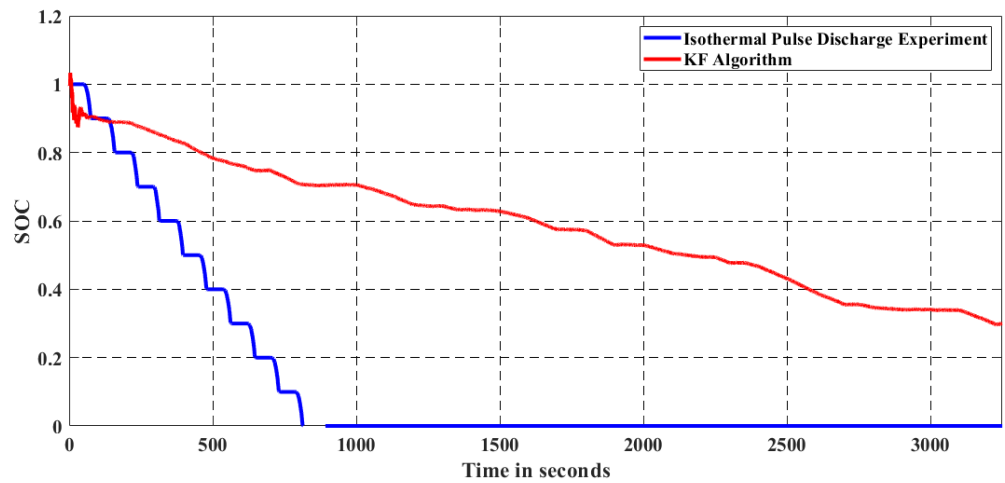

Figure 11. Estimated SoC comparison between the method in [16] and KF algorithm

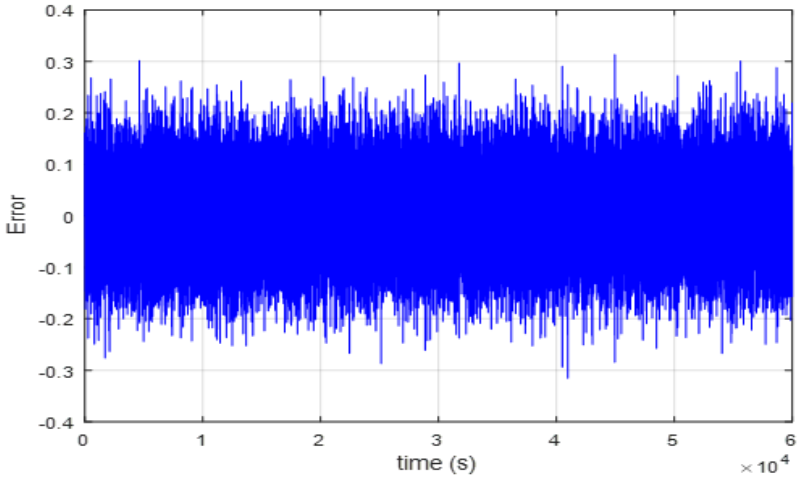

Figure 12. Voltage error recorded over time error remains in the acceptance band

The model is simulated for the assumption of $60 \%$ and $70 \%$ SoC to check the error covariance. Table 2 shows the comparison between the measured error covariance and estimated error covariance for $50 \%, 60 \%$ and $70 \%$ SoC.

Table 2. Measured \& estimated Voltage error covariance by KF algorithm

\begin{tabular}{cccc}
\hline SoC & $50 \%$ & $60 \%$ & $70 \%$ \\
\hline $\begin{array}{c}\text { Measured Error } \\
\text { Covariance }\end{array}$ & 1.0014 & 1.0014 & 1.0014 \\
$\begin{array}{c}\text { Estimated Error } \\
\text { Covariance }\end{array}$ & 0.0055 & 0.0033 & 0.0047 \\
\hline
\end{tabular}

\section{CONCLUSION}

The battery monitoring system is mainly used for calculating necessary data and using it to keep battery operating within its limits, so as not to damage it. Thus BMS forms a central part of Battery Management unit. By finalising state operations, it is possible to estimate and predict operating values, such as terminal voltage for battery. With this estimation, well known Kalman Filter algorithm technique is useful to estimate the SoC of Li-ion battery. Kalman Filter is an accurate algorithm for estimation, and that can be observed from error difference recorded over time. Even the small error is observed compared to measurement noise. KF is accurate for dynamic systems prediction process. From the parameter monitoring and parameter estimation of the battery model, it is concluded that the health of the battery can be analysed and the same has been done as per the results shown. 


\section{REFERENCES}

[1] Lu, Languang, Xuebing Han, Jianqiu Li, Jianfeng Hua, Minggao Ouyang, "A review on the key issues for lithiumion battery management in electric vehicles," Journal of power sources, vol. 226, pp. 272-288, 2013.

[2] Kim, Jonghoon, Bo-Hyung Cho, "State-of-charge estimation and state-of-health prediction of a Li-ion degraded battery based on an EKF combined with a per-unit system," IEEE Transactions on Vehicular Technology, vol. 60(9), pp. 4249-4260, 2011.

[3] He, Zhiwei, Mingyu Gao, Jie Xu., "EKF-Ah based state of charge online estimation for lithium-ion power battery," IEEE International Conference on Computational Intelligence and Security, vol. 1, pp. 142-145, 2009.

[4] Verbrugge, Mark, Edward Tate., "Adaptive state of charge algorithm for nickel metal hydride batteries including hysteresis phenomena," Journal of Power Sources, vol. 126(1), pp. 236-249, 2004.

[5] Plett, Gregory L., "Extended Kalman filtering for battery management systems of LiPB-based HEV battery packs: Part 3. State and parameter estimation," Journal of Power sources, vol. 134(2), pp. 277-292, 2004.

[6] Chaturvedi, Nalin A., Reinhardt Klein, Jake Christensen, Jasim Ahmed, and Aleksandar Kojic. "Algorithms for advanced battery-management systems," IEEE Control Systems 30, no.3, pp. 49-68, 2010.

[7] Bandhauer, Todd M., Srinivas Garimella, Thomas F. Fuller., "A critical review of thermal issues in lithium-ion batteries," Journal of the Electrochemical Society, vol. 158(3), R1-R25, 2011.

[8] Gaoussou Hadia F, Youtong Z., "Electro-thermal Modeling of Lithium-Ion Batteries," TELKOMNIKA Indonesian Journal of Electrical Engineering, vol 12(5), pp. 3671-3677, 2014.

[9] Saberi, H., Salmasi FR., "Genetic optimization of charging current for lead-acid batteries in hybrid electric vehicles," IEEE-International Conference on Electrical Machines and Systems, pp. 2028-2032, 2007.

[10] Ting, T.O., Ka Lok Man, Nan Zhang, Chi-Un Lei, Chao Lu., "State-space battery modeling for smart battery management system," International MultiConference of Engineers and Computer Scientists, Hong Kong, pp. 866869, 2014.

[11] Bhangu, Bikramjit S., Paul Bentley, David A. Stone, Christopher M. Bingham., "Nonlinear observers for predicting state-of-charge and state-of-health of lead-acid batteries for hybrid-electric vehicles," IEEE Transactions on Vehicular Technology, vol. 54(3), pp. 783-794, 2005.

[12] Kalman, Rudolph Emil., "A new approach to linear filtering and prediction problems," Journal of Basic Engineering, vol. 82(1), pp. 35-45, 1960.

[13] Medora, Nosh K., Alexander Kusko., "Dynamic battery modeling of lead-acid batteries using manufacturers' data," $27^{\text {th }}$ International Telecommunications Conference, Germany, pp. 227-232, 2005.

[14] Le, Daniel, Xidong Tang., "Lithium-ion battery state of health estimation using Ah-V characterization," Annual Conference of Prognostics and Health Management, Canada, vol. 2529, pp. 367-373, 2011.

[15] Ahasan Habib. AKM, Motakabber. SMA, Muhammad I. Ibrahim., "A series regeneration converter technique for voltage balancing of energy storage devices," Indonesian Journal of Electrical Engineering and Computer Science, vol. 8(2), pp. 475-481, 2017.

[16] Huria, T, Ceraolo, M, Gazzarri, J, Jackey, R., "High fidelity electrical model with thermal dependence for characterization and simulation of high power lithium battery cells," IEEE- International Electric Vehicle Conference, Greenville, pp. 1-8, 2012. 